\title{
Provision of Preventive Dental Services in Children Enrolled in Medicaid by Nondental Providers
}

Tania Arthur, DDS, MPHa R. Gary Rozier, DDS, MPH

OBJECTIVES: Aims of this study are to determine (1) the association of oral health services (OHS) provided by nontraditional providers with the percentage of Medicaid children 0 to 5 years of age who receive $\geq 1$ preventive services from all provider types in the United States; and (2) characteristics of state Medicaid policies associated with provision of OHS. METHODS: We conducted a time-series cross-sectional study of preventive services provided by nontraditional (OHS) and dental (PDS) providers for Medicaid-enrolled children from birth to 5 years of age in all states during 2010 to 2013 (204 observations). We applied panel data multiple regression analysis techniques to exploit year and state variation in aggregate data available in Centers for Medicare and Medicaid Services reports (form CMS416). Total preventive dental services (TPDS $=$ OHS + PDS) was predicted by months since state enactment of a policy to reimburse medical providers for OHS.

RESULTS: The 44 states with a policy reported $4.3 \%$ of children per state per year with any OHS. For all states, an average of $30.1 \%$ received PDS and 34.5\% TPDS. The delivery of OHS was associated with a small increase in percentage with TPDS. One year of Medicaid OHS availability was associated with an increase of $1.5 \%$ in the percentage of children with TPDS per state per year.

CONCLUsIONS: Implementation of policies by Medicaid programs to support integration of OHS into primary care is associated with increases in overallTPDS use, but efforts are needed to improve implementation in practice to achieve national impact on access.

${ }^{a}$ NYU Lutheran Department of Dental Medicine, Dental Public Health Residency Program, Brooklyn, New York; and ${ }^{b}$ Department of Health Policy and Management, Gillings School of Global Public Health, University of North Carolina at Chapel Hill, Chapel Hill, North Carolina

Dr Arthur acquired data and reviewed and revised the manuscript; Dr Rozier contributed to the analysis and interpretation of data and drafting and revising the manuscript; and both authors contributed to conception and design of the study and approved the final manuscript as submitted.

DOI: $10.1542 /$ peds.2015-3436

Accepted for publication Nov 19, 2015

Address correspondence to Tania Arthur, DDS, MPH, 4207 Tree Crossing Pkwy, Hoover, AL 35244. E-mail: taniamc18@hotmail.com

PEDIATRICS (ISSN Numbers: Print, 0031-4005; Online, 1098-4275).

Copyright @ 2016 by the American Academy of Pediatrics

FINANCIAL DISCLOSURE: The authors have indicated they have no financial relationships relevant to this article to disclose.

FUNDING: Funding for Dr Arthur was provided by NYU Lutheran Dental Public Health Residency.

POTENTIAL CONFLICT OF INTEREST: The authors have indicated they have no potential conflicts of interest to disclose.
WHAT'S KNOWN ON THIS SUBJECT: Most state Medicaid programs reimburse medical providers for provision of preventive oral health services. Evidence from a few states suggests that these services in medical offices increase access to preventive dental services and reduce treatment, avert hospitalizations, and save money.

WHAT THIS STUDY ADDS: This study provides the first national estimates of the percentage of 0 - to 5 -year-old children enrolled in Medicaid who receive oral health services from nondental providers and the impact on overall use of preventive dental services from all types of providers.

To cite: Arthur T and Rozier RG. Provision of Preventive Dental Services in Children Enrolled in Medicaid by Nondental Providers. Pediatrics. 2016;137(2):e20153436 
Concerns about the prevalence of dental disease among American children and barriers that prevent them from gaining access to dental care have contributed to a national discussion about potential solutions. Many highly visible organizations have highlighted the public health problems presented by dental disease and recommended strategies to help resolve problems. ${ }^{1-4}$

Much of the national discussion about oral health has centered on the performance of public insurance programs. In 2013, 37\% of children in the United States were enrolled in Medicaid Early and Periodic Screening, Diagnostic, and Treatment (EPSDT) or Children's Health Insurance Program (CHIP), amounting to $>38$ million children. ${ }^{5}$ An issue brief from the Children's Dental Health Project documented 7 hearings in the US Congress and 13 studies by the Government Accountability Office over 10 years starting in 2002 that focused on oral health issues. ${ }^{6}$ One of these reports, published in 2008, estimated that 1 in 3 children 2 to 18 years of age enrolled in Medicaid was affected by oral disease. Approximately 1 in 9 had untreated disease, amounting to 6.5 million children. ${ }^{7}$

One innovative strategy used to increase dental access is to reimburse medical providers for providing preventive dental services (PDS). Medicaid programs have taken the lead in encouraging nondental professionals to include preventive oral health services (OHS) in well child care. ${ }^{8}$ Because children frequently visit primary care doctors during their first 2 years of life, many opportunities exist to promote oral health in these settings. ${ }^{9}$ By 2015, 49 of the 50 state Medicaid programs included this benefit for young children. ${ }^{10}$

Studies in $\geq 6$ states suggest that preventive dental interventions provided in medical offices will increase access to preventive services, ${ }^{11-15}$ but their national impact on use of prevention dental services is unknown. All major dental organizations and most state Medicaid programs recommend that children initiate preventive dental visits by 12 months of age, ${ }^{16}$ yet infants and toddlers are the least likely children of any age to have a dental visit. Griffin et al $^{17}$ reported that only $1.7 \%$ of 0 - to 2 -year-olds had preventive dental visits with fluoride applications.

The purpose of this study is to determine the impact of Medicaid program reimbursement policies for OHS provided by nontraditional dental providers on utilization of preventive services for young children 0 through 5 years of age. The specific aims are to examine (1) the association of OHS provided by nontraditional providers with the overall percentage of children enrolled in Medicaid who receive $\geq 1$ preventive services provided by nondental and dental providers in the United States; and (2) characteristics of state policies associated with provision of OHS provided by nontraditional providers.

\section{METHODS}

We conducted a time-series crosssectional study of preventive services provided by medical and dental providers for Medicaid-enrolled children from birth to 5 years of age in all states and the District of Columbia during 2010 to 2013. Four years of consecutive annual time series data for each of the 51 states provided a balanced panel of 204 observations for the primary analysis. Institutional review board disposition was obtained from Lutheran Medical Center Health System.

\section{Data Sources}

We extracted data for use in the study from the State Annual EPSDT Participation Report (CMS-416) for
Federal Fiscal Years 2010 (October 2009 to September 2010) through 2013 (October 2012 to September 2013). This source provides aggregate administrative data reported by the states. We included the total unduplicated number of individuals who were enrolled in Medicaid or a CHIP Medicaid expansion program and determined to be eligible for EPSDT for $\geq 90$ continuous days (line $1 \mathrm{~b}$ ), total number receiving PDS from a dentist or by a dental provider under the supervision of a dentist (line 12b), and total number receiving OHS provided by any health care provider who is not a dentist or not supervised by a dentist (line12f) for 3 age groups ( $<1$ year, 1-2 years, and 3-5 years).

We were unable to determine whether services reported in line $12 \mathrm{f}$ were delivered by medical providers or unsupervised dental hygienists. To test for bias in our estimates of policy effect, we conducted a sensitively analysis in which we considered preventive services in states that allow direct access to dental hygienists and those that allow direct reimbursement of dental hygienists by Medicaid. ${ }^{18-20}$ We considered the services reported in line $12 \mathrm{f}$ to be preventive services because of the young ages selected for study and dental practice acts, which prohibit treatment by nondentists. The time series started in 2010 because it was the first year that the Centers for Medicare and Medicaid Services (CMS) reported OHS provided by nondentist providers. The denominator for calculation of utilization rates was the number in the selected age group who were enrolled in EPSDT or CHIP for $\geq 90$ continuous days as recommended by the Dental Quality Alliance. ${ }^{21}$

For the second study aim, we added information about reimbursement policies for nondentist OHS from state-specific information maintained by the American Academy of Pediatrics on its Web site ${ }^{10}$ and from 
1 published study on adoption of physician-delivered PDS. ${ }^{22}$

\section{Dependent Variables}

The primary outcome variable for the first study aim was the proportion of enrolled children who received any PDS, calculated as the sum of the percentage of enrolled children 0 to 5 years of age who received $\geq 1$ dental service from nondentists (referred to throughout as OHS, as recommended by CMS) and by or under the supervision of a dentist (referred to throughout as PDS). The sum of the 2 is referred to as total preventive dental services (TPDS). Preventive procedures are defined by Healthcare Common Procedure Coding System codes D1000 to D1999 (or equivalent Code on Dental Procedures and Nomenclature codes D1000 to D1999 or equivalent Current Procedural Terminology code). ${ }^{23}$ For the second study aim, we limited the analysis to the subgroup of states that reported implementation of OHS and focused on these services alone.

\section{Independent Variables}

The primary independent variable used for the first aim was number of months since state adoption of a policy to reimburse nondentists for OHS. For the second aim, we considered 2 variables calculated from the date of Medicaid program benefit adoption in addition to implementation months: baseline months of implementation and stage of adoption categories $1=$ innovator/early adopter [before 2006]; 2 = majority adopter [2006 to 2009]; and 3 = late adopter [after 2009]). Binary variables were included in the analysis for the second aim to indicate the comprehensiveness of preventive OHS (fluoride varnish only versus other in addition to fluoride varnish, such as screening, risk assessment, or counseling) and training requirements (yes versus no). We included a variable for the fee (in dollars) paid to nondentist providers for OHS by using the most recent estimate to adjust for inflation. We summed the rates for all dental procedures for those states that reimburse for $>1$ procedure and averaged the rate for those states that pay $>1$ rate for the same procedure.

\section{Statistical Analysis \\ Descriptive Analysis}

State- and year-specific variations in outcomes were explored descriptively. For each state, we calculated the mean percentage of enrolled children 0 to 5 years of age per year with $\geq 1$ OHS or PDS (Table 1). We also calculated mean change in these percentages by averaging differences in estimates for adjacent years. We display state estimates for the outcomes pooled across years in graphic form (Fig 1). Year effects for each of the outcomes were explored descriptively in pooled state data stratified by age group and overall (Table 2; Fig 2). Differences in means by year were tested by using analysis of variance (ANOVA) $F$ tests.

The second aim was limited to states in which Medicaid programs had adopted a policy to reimburse nondentists and in which CMS-416 reports demonstrated evidence of provider-level implementation, defined as a value $>0$ for the number of OHS in each of the reporting years. The percentage of children who received OHS was compared by the various levels of the independent variables and tested descriptively by using ANOVA.

\section{Model Selection and Specification}

We estimated linear regression models to examine the effects of Medicaid preventive oral health benefits provided by nondentists on the percentage of 0 - to 5 -year-old children with TPDS. We applied panel data multiple regression analysis techniques to exploit both time-series and cross-sectional variation in the data and to control for unobserved factors that might bias results. ${ }^{24}$

We followed the steps for the regression analyses ${ }^{25}$ recommended by Park ${ }^{26}$ and used PANEL Procedure Software, version 9.3, of the SAS System (SAS Institute, Cary, NC). We tested for state-specific and year-specific fixed effects with the $F$ test, using dummy variables in separate regression models to determine the need to control for unexplained cross-sectional and time-series variation. We found state-specific fixed effects (Wald $F$ test $=252.315 ; P<.001$ ) but no yearspecific effects (Wald $F$ test $=2.009$; $P=.570$ ). However, we rejected use of a 1-way state fixed-effect model based on the Hausman test $(P>.1)$ and other statistical and substantive considerations in favor of a 1-way state random effects model, which offers improved efficiency over fixed-effects models. ${ }^{24}$ Statistically significant Breusch-Pagan Lagrange multiplier tests supported the use of random effects over a pooled analysis in all regression models.

\section{RESULTS}

States demonstrated considerable variation in estimates for OHS, PDS, and TPDS (Table 1; Fig 1). In the 44 states adopting a policy to reimburse primary care providers for OHS, an average of $4.38 \%$ of children 0 to 5 years of age received OHS per state per year. This number increased by an average of 0.29 percentage points during the 4 years. The percentage of children 0 to 5 years of age with PDS for all 51 states averaged 30.1\% per state per year. Most states experienced an increase in this percentage over time, resulting in an average increase of $1.14 \%$ per state per year.

The percentages of children who received services varied by age (Table 2; Fig 2). A larger percentage of 12- to 35-month-old children received OHS than the other 2 age 
TABLE 1 Mean Percentage Enrolled and Percentage With OHS or PDS by State, Birth Through 5 y of Age, 2010-2013

\begin{tabular}{|c|c|c|c|c|c|c|}
\hline \multirow[t]{2}{*}{ State } & \multirow{2}{*}{$\begin{array}{l}\text { Policy Adoption } \\
\text { Date }\end{array}$} & \multirow{2}{*}{$\begin{array}{l}\text { Mean Enrollment, } \\
\qquad n^{\mathrm{a}}\end{array}$} & \multicolumn{2}{|c|}{$\mathrm{OHS}^{\mathrm{b}}$} & \multicolumn{2}{|c|}{ PDS $^{c}$} \\
\hline & & & Mean \% per Yeard & $\begin{array}{l}\text { Mean Change in } \\
\text { Percentage Points }\end{array}$ & Mean \% per Yeard & $\begin{array}{l}\text { Mean Change in } \\
\text { Percentage Points }\end{array}$ \\
\hline Alabama & January 2009 & 217800 & $2.34(0.17)$ & $0.06(0.27)$ & $34.69(0.75)$ & $0.50(1.27)$ \\
\hline Alaska & July 2010 & 32543 & $0^{\mathrm{e}}$ & - & $26.08(1.44)$ & $0.96(1.18)$ \\
\hline Arizona & - & 282696 & $-^{f}$ & - & $29.35(1.13)$ & $0.91(1.24)$ \\
\hline Arkansas & - & 148056 & - & - & $31.12(1.62)$ & $1.19(0.77)$ \\
\hline California & June 2006 & 1598631 & $3.16(0.61)$ & $0.24(0.87)$ & $25.96(1.35)$ & $1.03(0.75)$ \\
\hline Colorado & July 2009 & 168347 & $6.00(3.24)$ & $2.39(1.48)$ & $39.21(2.97)$ & $1.98(2.86)$ \\
\hline Connecticut & November 2008 & 101706 & $2.87(1.62)$ & $1.18(0.77)$ & $45.51(2.12)$ & $2.28(1.64)$ \\
\hline District of Columbia & - & 32415 & - & - & $37.63(3.77)$ & $2.32(4.51)$ \\
\hline Delaware & - & 37144 & - & - & $27.44(2.90)$ & $2.11(1.18)$ \\
\hline Florida & April 2008 & 771299 & $6.32(2.49)$ & $1.59(1.90)$ & $10.95(3.56)$ & $2.19(3.37)$ \\
\hline Georgia & August 2010 & 461891 & $1.84(2.29)$ & $1.58(1.40)$ & $32.55(1.80)$ & $1.29(1.29)$ \\
\hline Hawaii & - & 50078 & - & - & $35.34(6.07)$ & $-3.56(7.58)$ \\
\hline Idaho & November 2002 & 71498 & $0.06(0.04)$ & $-0.3(0.03)$ & $34.31(2.06)$ & $1.09(2.36)$ \\
\hline Illinois & July 2007 & 537485 & $2.79(1.34)$ & $1.01(0.19)$ & $42.81(3.62)$ & $2.48(0.81)$ \\
\hline Indiana & - & 257252 & - & - & $17.33(2.94)$ & $2.00(3.72)$ \\
\hline lowa & January 2001 & 107991 & $22.8(14.53)$ & $-8.49(21.18)$ & $32.13(8.50)$ & $6.19(4.94)$ \\
\hline Kansas & September 2005 & 103273 & $4.93(1.22)$ & $-0.73(1.39)$ & $27.60(2.42)$ & $1.65(2.13)$ \\
\hline Kentucky & July 2007 & 184284 & $0.81(0.69)$ & $-0.48(0.34)$ & $28.09(1.85)$ & $-0.37(3.29)$ \\
\hline Louisiana & September 2012 & 267410 & $0.04(0.05)$ & $0.03(0.98)$ & $35.37(2.86)$ & $1.98(2.42)$ \\
\hline Maine & September 2008 & 41325 & $15.28(6.43)$ & $3.55(7.41)$ & $20.07(6.58)$ & $5.30(3.87)$ \\
\hline Maryland & July 2009 & 215202 & $6.67(1.17)$ & $0.95(0.97)$ & $38.83(1.36)$ & $0.92(2.15)$ \\
\hline Massachusetts & October 2008 & 187013 & $4.02(1.98)$ & $1.52(0.54)$ & $35.09(2.57)$ & $2.03(0.45)$ \\
\hline Michigan & January 2008 & 386431 & $3.86(0.56)$ & $-0.36(0.81)$ & $23.44(1.34)$ & $1.05(0.51)$ \\
\hline Minnesota & August 2008 & 164597 & $9.99((1.72)$ & $1.40(1.25)$ & $22.04(2.50)$ & $0.06(5.01)$ \\
\hline Mississippi & July 2010 & 160183 & $4.83(3.23)$ & $2.62(1.58)$ & $33.46(2.30)$ & $1.66(1.13)$ \\
\hline Missouri & November 2008 & 229587 & $1.10(0.67)$ & $0.50(0.92)$ & $19.33(1.95)$ & $1.52(0 / 43)$ \\
\hline Montana & October 2008 & 31137 & $6.00(3.98)$ & $-2.54(4.84)$ & $30.66(4.25)$ & $2.95(2.16)$ \\
\hline Nebraska & April 2009 & 66977 & $2.96(0.50)$ & $0.31(0.63)$ & $32.33(2.18)$ & $1.70(1.06)$ \\
\hline Nevada & January 2007 & 94524 & $7.06(1.03)$ & $-0.60(1.42)$ & $24.83(2.75)$ & $2.21(0.91)$ \\
\hline New Hampshire & - & 31790 & - & - & $37.42(1.30)$ & $1.02(0.38)$ \\
\hline New Jersey & July 2010 & 249819 & 0 & - & $31.69(2.91)$ & $2.28(2.14)$ \\
\hline New Mexico & July 2009 & 124124 & $3.30(1.00)$ & $-0.57(1.06)$ & $35.24(2.84)$ & $2.00(1.40)$ \\
\hline New York & October 2009 & 778331 & $6.82(0.85)$ & $0.50(0.85)$ & $24.14(1.75)$ & $1.39(0.69)$ \\
\hline North Carolina & February 2000 & 431302 & $20.62(0.83)$ & $0.56(0.61)$ & $33.12(2.56)$ & $1.83(1.14)$ \\
\hline North Dakota & January 2008 & 19600 & 7.44 (2.79) & $1.94(2.53)$ & $17.20(0.94)$ & $-0.57(1.67)$ \\
\hline Ohio & July 2006 & 429799 & $2.36(0.75)$ & $-0.22(1.34)$ & $21.40(7.93)$ & $-5.85(12.11)$ \\
\hline Oklahoma & July 2011 & 203249 & $0.36(0.41)$ & $0.24(0.39)$ & $28.51(0.85)$ & $-0.30(1.59)$ \\
\hline Oregon & July 2002 & 133566 & $2.23(0.82)$ & $0.56(0.67)$ & $27.07(2.22)$ & $1.53(1.76)$ \\
\hline Pennsylvania & April 2010 & 397929 & $1.94(1.51)$ & $1.19(0.32)$ & $25.18(2.14)$ & $1.51(1.66)$ \\
\hline Rhode Island & November 2008 & 34905 & $1.53(0.83)$ & $0.45(0.918)$ & $26.04(1.08)$ & $-0.36(1.86)$ \\
\hline South Carolina & August 2007 & 217087 & $1.88(0.76)$ & $0.53(0.36)$ & $36.26(1.13)$ & $0.26(1.89)$ \\
\hline South Dakota & January 2007 & 32565 & $0.84(0.33)$ & $0.25(0.07)$ & $30.24(1.76)$ & $-0.01(3.09)$ \\
\hline Tennessee & July 2011 & 277976 & 0 & - & $29 / 25(2.20)$ & $1.55(1.37)$ \\
\hline Texas & September 2008 & 1297099 & $9.35(1.36)$ & $0.0 .98(0.92)$ & $34.57(1.35)$ & $-0.89(0.91)$ \\
\hline Utah & October 2006 & 97783 & $0.71(0.25)$ & $0.07(0.41)$ & $34.47(1.24)$ & $0.79(1.00)$ \\
\hline Vermont & September 2008 & 19596 & $4.12(0.87)$ & $0.66(0.39)$ & $39.17(1.34)$ & $0.85(1.21$ \\
\hline Virginia & January 2008 & 233059 & $1.84(0.57)$ & $0.43(0.28)$ & $32.59(1.61)$ & $1.21(0.75)$ \\
\hline Washington & April 1998 & 274328 & $22.06(3.31)$ & $2.06(4.85)$ & 47.38 (2.39) & 1.74 (1.69) \\
\hline West Virginia & July 2012 & 72307 & $0.02(0.00)$ & $-0.01(0.00)$ & $32.00(1.85)$ & $1.02(2.01)$ \\
\hline Wisconsin & February 2004 & 191313 & $12.82(2.26)$ & $0.18(3.92)$ & $14.60(0.73)$ & $0.49(0.59)$ \\
\hline Wyoming & January 2007 & 21813 & $6.41(1.00)$ & $-0.70(0.50)$ & $26.64(2.11)$ & $-1.13(3.42)$ \\
\hline All & & 246630 & $4.38(6.01)$ & $0.29(3.22)$ & $30.15(7.91)$ & $1.14(2.96)$ \\
\hline
\end{tabular}

a Mean of 4-y enrollment for $\geq 90$ continuous days each year.

${ }^{\mathrm{b}} n=176$.

${ }^{\mathrm{c}} n=204$.

d Mean (SD) of 4 y for each state.

e Reimbursement policy adopted but no OHS services reported.

${ }^{f}$ No reimbursement policy adopted by state Medicaid program. 
groups, and a larger percentage of 36- to 71-month-old children received PDS compared with other ages.

\section{Aim 1: Impact of Policy for OHS on TPDS}

The average number of months since program adoption for the complete panel of 204 observations was 47.3 months (SD 40.93). In pooled bivariate analyses, number of months of program adoption was positively correlated with percent of 0-year-olds (Pearson correlation coefficient $[r]=0.507 ; P<.001), 1$ - to 2 -year-olds $(r=0.557 ; P<.001)$, 3 to 5-year-olds $(r=0.316 ; P<.001)$, and all ages combined $(r=0.454 ; P<$ .001) receiving $\geq 1$ TPDS.

Months since program adoption was associated at a statistically significant level with the provision of TPDS in regression models stratified by age and for all ages combined in the complete panel of 204 observations (Table 3). On average, 1 year of policy adoption was associated with a 1.5-percentage-point increase in TPDS.

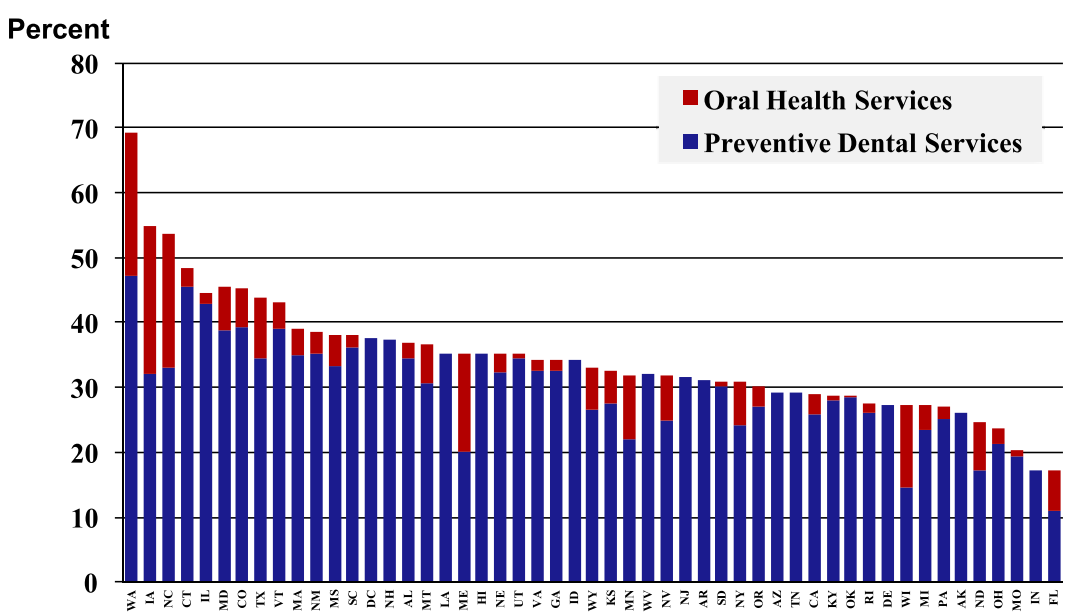

FIGURE 1

Mean percentage of children 0 to 5 years of age enrolled in Medicaid with any OHS or PDS, United States, 2010-2013.

\section{Aim 2: Factors Associated With Provision of Preventive OHS}

The analysis for the second aim was limited to the 38 states that had reported use of OHS for all 4 years, or a balanced panel of 152 observations. Of these observations, 32 (21.0\%) were classified as early adopters, $108(71.0 \%)$ as majority adopters, and $12(7.8 \%)$ as late adopters. The majority of state observations (108; $71.0 \%$ ) provided reimbursement for fluoride varnish only and required training of some type $(n=100$; $65.7 \%$ ). The average number of months per state per year that the program had been in place before 2010 was 32.3 (SD 34.37), and the average reimbursement amount per state per year was $\$ 25.80$ (SD \$13.22; minimum \$9.00; maximum \$55.46).

Table 4 displays the association of each of the predictor variables with the percentage of children receiving

TABLE 2 Mean Enrollment and Percentage With Use of OHS or PDS by Age Group, 2010-2013

\begin{tabular}{|c|c|c|c|c|}
\hline \multirow[t]{2}{*}{ Age, mo } & \multicolumn{4}{|c|}{ Year } \\
\hline & 2010 & 2011 & 2012 & 2013 \\
\hline \multicolumn{5}{|l|}{$0-11$} \\
\hline Enrollment, $n$ & 34845 (43 053) & 35108 (44 303) & 34647 (43 219) & 34893 (43569) \\
\hline OHS, \% & $1.40(2.94)$ & $1.68(3.27)$ & $1.86(3.62)$ & $1.54(2.62)$ \\
\hline PDS, \% & $0.68(1.12)$ & $0.54(0.73)$ & $0.57(0.77)$ & $0.92(1.98)$ \\
\hline Both, \% & $2.09(3.11)$ & $2.22(3.47)$ & $2.43(3.83)$ & $2.46(3.40)$ \\
\hline \multicolumn{5}{|l|}{$12-35$} \\
\hline Enrollment, $n$ & 90499 (111769) & 89048 (108569) & $86948(106517)$ & 86068 (107 089) \\
\hline OHS, \% & $4.76(7.77)$ & $6.03(8.65)$ & $7.26(9.53)$ & $6.80(9.00)$ \\
\hline PDS, \% & $15.44(7.85)$ & $16.00(7.95)$ & 16.83 (8.33) & $18.61(6.56)$ \\
\hline Both, \% & $20.21(11.42)$ & $22.03(12.50)$ & 24.10 (13.59) & $25.41(13.36)$ \\
\hline \multicolumn{5}{|l|}{$36-71$} \\
\hline Enrollment, $n$ & $118258(143856)$ & $124593(149364)$ & $126441(152766)$ & $125147(156073)$ \\
\hline $\mathrm{OHS}, \%$ & $3.32(5.62)$ & $4.08(6.80)$ & $4.54(7.54)$ & $3.66(5.30)$ \\
\hline PDS, \% & $46.53(10.15)$ & 47.22 (10.49) & $48.63(10.28)$ & 49.58 (9.88) \\
\hline Both, \% & $49.86(10.57)$ & $51.30(11.25)$ & $53.17(11.41)$ & $53.25(10.38)$ \\
\hline \multicolumn{5}{|l|}{$0-71$} \\
\hline Enrollment, $n$ & 243622 (298 279) & $248750(301820)$ & 248037 (302 077) & 246109 (306301) \\
\hline $\mathrm{OHS}, \%$ & $3.56(5.39)$ & $4.42(6.27)$ & $5.09(6.93)$ & $4.44(5.39)$ \\
\hline PDS, \% & $28.42(7.53)$ & $29.51(7.94)$ & $30.80(8.00)$ & 31.85 (7.95) \\
\hline Both, \% & 31.99 (8.93) & 33.94 (9.94) & $35.92(10.43)$ & 36.29 (9.81) \\
\hline
\end{tabular}

Values are expressed as mean (SD) $n=51$ for each year. OHS delivered by nondental provider: PDS delivered by dental provider; Both, sum of OHS and PDS. Denominators for OHS and PDS are not unduplicated. $P$ values for trends by year in OHS, PDS, and Both for each age group are $>.1$ based on ANOVA F test. 


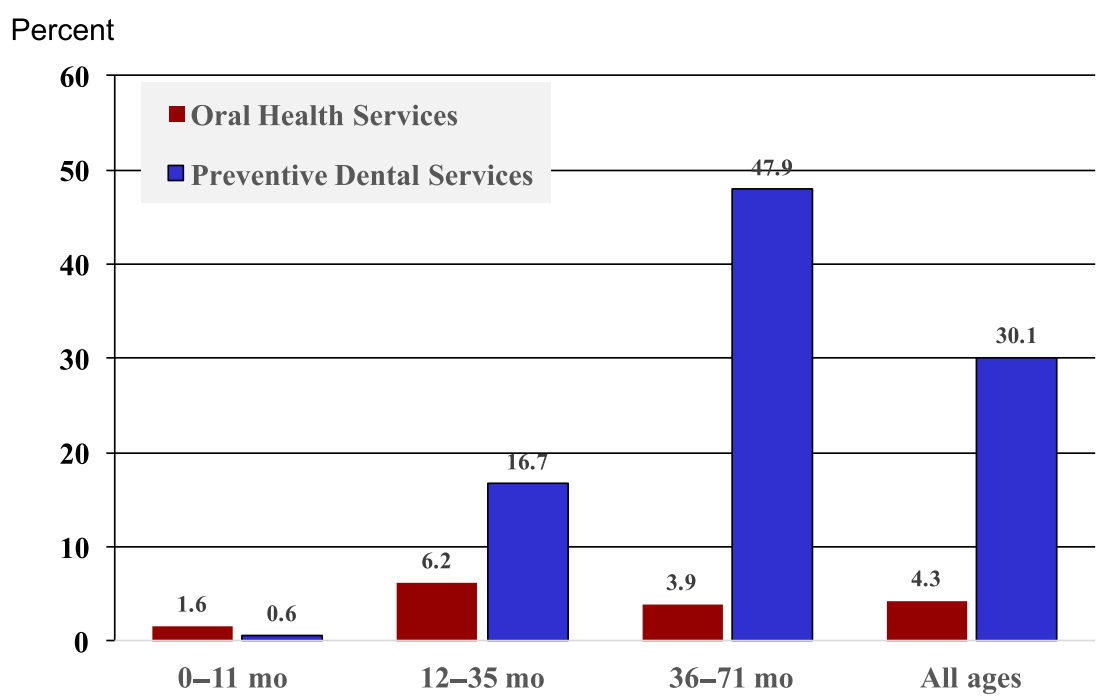

FIGURE 2

Mean percentage of children enrolled in Medicaid with any OHS or PDS, by age, United States, 2010-2013

OHS in a descriptive analysis by using data pooled by state and year. Most variables were associated with the outcome in all age groups. The only variable associated with $\mathrm{OHS}$ at a statistically significant level in any of the panel regression models was early adoption (Table 5). For all ages, the average effect of early adoption on OHS across time and between states compared with majority adopters was 8.1 percentage points.

\section{DISCUSSION}

This study provides the first attempt to determine the reach of Medicaid reimbursement policies for preventive OHS provided by nondentist providers into the young Medicaid population. We found that 44 state Medicaid programs reimbursed for provision of OHS in medical settings by 2013 . Yet nationally, implementation in primary care settings is low, with an average of only $4.3 \%$ of children 0 to 5 years of age receiving any OHS during 2010 to 2013.

We found large state-to-state variation in the delivery of OHS. The gap between having statelevel policies in place and delivery of services at the practice level observed in the overall sample has been narrowed in some individual states. More than $10 \%$ of children 0 to 5 years of age received OHS in 5 states (Iowa, Maine, North Carolina, Washington, and Wisconsin). With the addition of OHS, 5 states (Iowa, North Carolina, Maine, Minnesota, and Nevada) improved their state rankings in access to PDS by $>10$ positions. For example, Maine improved from 46th based on the average percent of children with PDS (mean $=20.1 \%$ per year) to 19 th based on TPDS $($ mean $=36.4 \%$ per year), or 27 places in the rankings. These findings suggest that the diffusion of OHS into medical practice can be increased, but little research has been done to understand characteristics of effective dissemination and implementation strategies for OHS.

Maine, ${ }^{15}$ North Carolina, ${ }^{27}$ and Washington ${ }^{11}$ are 3 of the more successful states that have documented their activities. All formed interprofessional coalitions of medicine, dentistry, and public health to participate in program development, but with a clearly identified lead organization to manage the activities. These partnerships refined existing networks to document the oral health problem and identify dissemination and implementation strategies, usually through an iterative participatory process of pilot testing, feedback, and resolution. To facilitate implementation, quality improvement efforts were undertaken and decision support tools were made available. Finally, ongoing monitoring and evaluation activities at state and local levels provided feedback on predetermined implementation benchmarks and outcomes.

Translation of evidence-based knowledge into widespread use is slow and often incomplete. ${ }^{28}$ Theories and conceptual frameworks identify important steps that can help accelerate the translation process. ${ }^{29,30}$ Several appear to align with approaches used in states that have been most successful in

TABLE 3 Regression Model Estimates for the Effect of Number of Months With State Providing OHS on TPDS, by Age Group, 2010-2013

\begin{tabular}{|c|c|c|c|c|c|c|c|c|}
\hline Model & Age, mo & $\begin{array}{c}\text { Cross-Sectional } \\
\text { Variance }\end{array}$ & $\begin{array}{c}\text { Error } \\
\text { Variance }\end{array}$ & Intercept & $\begin{array}{l}\text { Coefficient (SE) for } \\
\text { Months Implemented }\end{array}$ & $P$ & $\mathrm{R}^{2}$ & Hausman $M$ \\
\hline 1 & $0-11$ & 8.76 & 1.50 & 1.20 & $0.023(0.005)$ & $<.001$ & 0.071 & 0.015 \\
\hline 2 & $12-35$ & 97.92 & 15.88 & 14.68 & $0.174(0.019)$ & $<.001$ & 0.285 & 0.994 \\
\hline 3 & $36-71$ & 91.24 & 17.34 & 47.32 & $0.096(0.019)$ & $<.001$ & 0.107 & 0.628 \\
\hline 4 & $0-71$ & 67.60 & 11.29 & 28.52 & $0.127(0.016)$ & $<.001$ & 0.230 & 0.436 \\
\hline
\end{tabular}

$n=51$ states $\times 4 \mathrm{y}=204$ observations. One-way state random effects model with variance components estimated by using Wansabeek and Kapteyn method (groupwise heteroscedastic regression). Ftest for state 1 -way fixed effects for all age groups, $P<.001$. Breusch-Pagan Lagrange multiplier test $P$ values for time random effects all $>1$. 
TABLE 4 Mean Percentage of Children With Any OHS Provided by Nondentist Provider, by Predictor Variables and Age Group, 2010-2013

\begin{tabular}{|c|c|c|c|c|c|}
\hline \multirow[t]{2}{*}{ Variable Category } & \multirow[t]{2}{*}{ Sample Size (Column \%) ${ }^{a}$} & \multicolumn{3}{|c|}{ Age, mo } & \multirow[t]{2}{*}{ All Ages } \\
\hline & & $0-11$ & $12-35$ & $36-71$ & \\
\hline \multicolumn{6}{|l|}{ Implementation, mo } \\
\hline $0-39$ & $49(32.2)$ & $1.73(2.27)$ & $5.60(4.97)$ & $3.32(3.96)$ & $3.89(3.17)$ \\
\hline $40-64$ & $52(34.2)$ & $1.79(2.26)$ & $7.07(6.16)$ & $3.92(4.77)$ & $4.70(4.10)$ \\
\hline $65-186$ & $51(33.5)$ & $2.98(4.96)$ & $12.20(13.07)^{b}$ & $8.40(9.42)^{b}$ & $8.95(8.86)^{b}$ \\
\hline \multicolumn{6}{|l|}{ Baseline implementation months } \\
\hline $0-11$ & $48(31.5)$ & $1.52(1.81)$ & $5.57(4.49)$ & $2.71(3.25)$ & $3.52(2.48)$ \\
\hline $12-30$ & $48(31.5)$ & $2.29(2.76)$ & $7.58(6.69)$ & $4.60(5.43)$ & $5.30(4.50)$ \\
\hline $31-138$ & $56(36.8)$ & $2.63(4.76)$ & $11.31(12.75)^{\mathrm{b}}$ & $7.92(9.06)^{b}$ & $8.365(8.68)^{\mathrm{b}}$ \\
\hline \multicolumn{6}{|l|}{ Adoption stage } \\
\hline Early & $32(21.0)$ & $4.05(5.91)$ & $15.76(15.12)$ & $11.75(10.31)$ & $12.06(9.78)$ \\
\hline Majority & $108(71.0)$ & $1.68(2.19)$ & $6.53(5.56)$ & $3.64(4.34)$ & $4.36(3.61)$ \\
\hline Late & $12(7.8)$ & $1.54(2.08)^{\mathrm{b}}$ & $4.57(4.28)^{\mathrm{b}}$ & $2.08(2.54)^{\mathrm{b}}$ & $2.87(2.64)^{\mathrm{b}}$ \\
\hline \multicolumn{6}{|l|}{ Comprehensiveness } \\
\hline Fluoride varnish only & $108(71.0)$ & $1.38(3.28)$ & $5.70(6.02)$ & $4.71(6.41)$ & $4.56(5.39)$ \\
\hline Fluoride varnish and other & $44(28.9)$ & $4.12(3.06)^{b}$ & $14.75(12.25)^{\mathrm{b}}$ & $6.49(7.84)$ & $9.07(7.27)^{\mathrm{b}}$ \\
\hline \multicolumn{6}{|l|}{ Training required } \\
\hline Yes & $100(65.7)$ & $2.64(4.03)$ & $9.55(10.48)$ & $5.41(7.64)$ & $6.47((7.11)$ \\
\hline No & $52(34.2)$ & $1.27(1.52)^{b}$ & $5.94(5.55)^{\mathrm{b}}$ & $4.86(5.13)$ & $4.70(4.21)$ \\
\hline \multicolumn{6}{|l|}{ Reimbursement amount } \\
\hline$\$ 9-\$ 16$ & $52(34.2)$ & $1,53(4.41)$ & $5.73(7.57)$ & $5.59(8.144)$ & $5.07(7.27)$ \\
\hline$\$ 17-\$ 29$ & $48(31.5)$ & $1.40(1.85)$ & $5.62(4.72)$ & $2.88(3.676)$ & $3.60(2.59)$ \\
\hline$\$ 30-\$ 56$ & $52(34.2)$ & $3.52(3.10)^{b}$ & $13.39(11.61)^{b}$ & $7.04(7.249)^{b}$ & $8.75(6.70)^{\mathrm{b}}$ \\
\hline
\end{tabular}

Values are expressed as mean (SD). Seven nonadopting states; 3 adopted but no evidence of implementation (ie, no reimbursement); 3 states partial years of implementation.

a Pooled analysis; $n=38$ states $\times 4$ y $=152$ observations.

${ }^{b}$ ANOVA $P$ value $<.05$.

TABLE 5 Regression of Predictors of Percentage of Children With OHS Among State Medicaid Programs With Policy Implemented, by Age Group, 2010-2013

\begin{tabular}{|c|c|c|c|c|c|c|c|c|}
\hline \multirow[t]{3}{*}{ Variable } & \multicolumn{6}{|c|}{ Age Group, mo } & \multirow{2}{*}{\multicolumn{2}{|c|}{ All Ages }} \\
\hline & \multicolumn{2}{|c|}{$0-11$} & \multicolumn{2}{|c|}{$12-35$} & \multicolumn{2}{|l|}{$36-71$} & & \\
\hline & Estimate (SE) & $P$ & Estimate (SE) & $P$ & Estimate (SE) & $P$ & Estimate (SE) & $P$ \\
\hline \multicolumn{9}{|l|}{ Adoption status } \\
\hline Early versus majority & $2.52(1.10)$ & .024 & $10.138(2.65)$ & $<.001$ & $8.43(2.27)$ & $<.001$ & $8.19(1.00)$ & $<.001$ \\
\hline Late versus majority & $0.02(1.68)$ & .989 & $-2.155(4.05)$ & .322 & $-9.71(3.47)$ & .571 & $-1.70(2.74)$ & .534 \\
\hline $\begin{array}{l}\text { Fluoride varnish only versus } \\
\text { comprehensive }\end{array}$ & $-2.09(1.43)$ & .146 & $-5.322(3.44)$ & .124 & $-0.96(2.96)$ & .744 & $-2.78(2.33)$ & .235 \\
\hline Training required & $1.15(0.95)$ & .228 & $2.340(2.29)$ & .310 & $-0.47(1.97)$ & .811 & $0.80(1.55)$ & .606 \\
\hline Reimbursement amount, \$ & $0.03(0.05)$ & .459 & $0.200(0.12)$ & .097 & $0.05(0.10)$ & .594 & $0.09(0.08)$ & .223 \\
\hline Intercept & $1.40(2.24)$ & .531 & $3.400(5.37)$ & .528 & $3.18(4.61)$ & .491 & $3.14(3.64)$ & .390 \\
\hline Cross-section variance & 6.45 & & 38.49 & & 28.30 & & 17.04 & \\
\hline Error variance & 3.34 & & 14.06 & & 10.47 & & 9.30 & \\
\hline$R^{2}$ & 0.098 & & 0.191 & & 0.096 & & 0.179 & \\
\hline
\end{tabular}

Estimated with 1-way random effects model and Fuller and Battese variance components. $n=38$ states with evidence of implementation and 4 time periods (balanced) $=152$ observations

Seven states without adoption and 6 states with partial years or adopt but no implementation excluded from the analysis.

improving access to OHS and can provide guidance in undertaking dissemination interventions and related research.

Adoption stage, comprehensiveness of OHS included in the insurance benefit, training requirements, and reimbursement amounts were all associated with the provision of OHS in bivariate analyses. Adoption stage was the only variable significant in the multivariate analysis. An average of $12.0 \%$ of children 0 to 5 years of age per state per year used OHS among early-adopting states, compared with $4.3 \%$ for majority-adopting states and $2.8 \%$ for late-adopting states. After adoption of state Medicaid policies, OHS visits appear to be low initially but increase with time. ${ }^{12}$ The national rate of OHS is likely to increase as majority- and late-adopting states gain more experience.
The percentage of children 0 to 5 years of age with PDS visits averaged $30 \%$ per state per year. Dental visits by Medicaid children increased substantially during the last decade or more. ${ }^{31-34}$ Implementation of policies to support integration of OHS into primary care by state Medicaid programs appears to be associated with only a small portion of a continuing increase in use during 
2010 to 2013. On average, having a Medicaid policy in place for 1 year was associated with a 1.5-percentage-point increase in children receiving PDS from nondental and dental providers.

The literature and results of our study suggest that states that undertake comprehensive interventions to improve the delivery of preventive services in medical, dental, and public health settings can improve access. ${ }^{35}$ Delivery of OHS in primary care can provide a temporary dental home for those children who lack access or the motivation to seek care in a dental office and increase use of preventive services in the dental office if effective referral practices are followed. ${ }^{36,37}$ Studies show that physicians underrefer for oral health problems, ${ }^{38,39}$ so further research is needed to improve the linkage between medical and dental homes to help ensure continuous access to dental services beginning at $\sim 1$ year of age.

The CMS national reporting system did not allow us to unduplicate TPDS by service provider type, so we summed the separate counts of OHS and PDS to get an overall estimate of TPDS. A comparison of the reported unduplicated number of enrolled

\section{REFERENCES}

1. Oral Health in America. A Report of the Surgeon General. Rockville, MD: US Department of Health and Human Services; National Institute of Dental and Craniofacial Research, National Institutes of Health; 2000

2. Segura A, Boulter S, Clark M, et al; Section on Oral Health. Maintaining and improving the oral health of young children. Pediatrics. 2014;134(6):1224-1229

3. American Dental Association. State and Community Models for Improving Access to Dental Care for the Underserved: A White Paper. Chicago, IL: American Dental Association; 2004 children 0 to 5 years of age receiving any oral health or dental services, including diagnostic and treatment services, for the 2013 fiscal year with the sum of separately reported unduplicated medical and dental services suggests that the duplication rate is only $\sim 7 \%$.

Most analysts believe that the CMS-416 system underreports utilization. ${ }^{40,41}$ The potential also exists for misclassification of OHS, because we were unable to separate preventive services provided in medical settings from those provided by unsupervised dental hygienists in public health settings. Our sensitivity analysis found that the coefficient for implementation months was unchanged when we included a covariate in regression models for direct access states or direct Medicaid reimbursement states for dental hygienists. The prevalence estimate for the percentage with OHS might be overestimated, but the effect of implementation months should be biased only to the extent that misclassification results in an attenuation of the effect. Finally, preventive services are not reported separately from treatment services for nontraditional providers, but this is unlikely to represent a concern.

4. Institute of Medicine. Advancing Oral Health in America. Washington, DC: The National Academies Press; 2011

5. The Center for Medicaid and CHIP Services (CMCS). Annual EPSDT Participation Report, Form CMS-416 (National), Fiscal Year: 2013. Available at: www.medicaid.gov/medicaidchip-program-information/by-topics/ benefits/downloads/form-416.zip. Accessed July 17, 2015

6. Edelstein BL. Dental visits for Medicaid Children: Analysis \& policy recommendations. Children's Dental Health Project Issue Brief. June 2012.

\section{CONCLUSIONS}

Our study finds that policies to support integration of OHS into nontraditional settings such as medical practice are widespread among state Medicaid programs and are associated with an overall increase in preventive services for children 0 to 5 years of age. But diffusion into primary care is progressing slowly, and only a small percentage of Medicaidenrolled children are receiving OHS. Little translational research has been done on dissemination and implementation of OHS, but earlyadopting states can provide insights into successful strategies that can be used to improve access to PDS in medical and dental settings.

\section{ABBREVIATIONS}

ANOVA: analysis of variance

CHIP: Children's Health Insurance Program

CMS: Centers for Medicare and Medicaid Services

EPSDT: Early and Periodic Screening, Diagnostic, and Treatment

OHS: oral health services PDS: preventive dental services TPDS: total preventive dental services
Available at: www.cdhp.org/resources/ 173-dental-visits-for-medicaid-childrenanalysis-policy-recommendations. Accessed August 8, 2015

7. General Accountability Office. Medicaid: Extent of dental disease in children has not decreased, and millions are estimated to have untreated tooth decay. GA0-08-1121. September 23, 2008. Available at: www.gao.gov/products/ GA0-08-1121. Accessed July 20, 2015

8. Cantrell C. Engaging primary care medical providers in children's oral health. Portland, ME: National Academy for State Health Policy, September 
2009. Available at: www.nashp.org/ sites/default/files/EngagingPrimaryCa reMedicalProvidersCOH.pdf. Accessed July 20, 2015

9. Mouradian WE, Schaad DC, Kim $S$, et al. Addressing disparities in children's oral health: a dentalmedical partnership to train family practice residents. J Dent Educ. 2003;67 (8):886-895

10. American Academy of Pediatrics. Children's oral health: state information and resources map. Available at: www2.aap.org/ commpeds/dochs/oralhealth/state. html. Accessed July 22, 2015

11. Riter D, Maier R, Grossman DC. Delivering preventive oral health services in pediatric primary care: a case study. Health Aff (Millwood). 2008;27(6):1728-1732

12. Rozier RG, Stearns SC, Pahel BT, Quinonez RB, Park J. How a North Carolina program boosted preventive oral health services for low-income children. Health Aff (Millwood). 2010;29(12):2278-2285

13. Okunseri C, Szabo A, Jackson S, Pajewski NM, Garcia RI. Increased children's access to fluoride varnish treatment by involving medical care providers: effect of a Medicaid policy change. Health Serv Res. 2009;44(4):1144-1156

14. Herndon JB, Tomar SL, Catalanotto FA, Vogel WB, Shenkman EA. The effect of Medicaid primary care provider reimbursement on access to early childhood caries preventive services. Health Serv Res. 2015;50(1):136-160

15. Gray C, Fox K. Improving Health Outcomes for Children (IHOC). First STEPS Phase III Initiative: Improving oral health and healthy weight in children. Final Evaluation Report. Muskie School of Public Service, University of Southern Maine. May 2015. Available at: www.maine.gov/ dhhs/oms/pdfs_doc/ihoc/First $\% 20$ STEPS_Phase\%20III\%20report\%20final. pdf. Accessed July 20, 2015

16. Douglass JM, Clark MB. Integrating oral health into overall care to prevent early childhood caries: need, evidence, and solutions. Pediatr Dent. 2015;37(3):266-274

17. Griffin SO, Barker LK, Wei L, Li CH, Albuquerque MS, Gooch BF; Centers for Disease Control and Prevention (CDC). Use of dental care and effective preventive services in preventing tooth decay among U.S. children and adolescents-Medical Expenditure Panel Survey, United States, 2003-2009 and National Health and Nutrition Examination Survey, United States, 2005-2010. MMWR Surveill Summ. 2014;63 (suppl 2):54-60

18. Naughton DK. Expanding oral care opportunities: direct access care provided by dental hygienists in the United States. J Evid Based Dent Pract. 2014;14(suppl):1 71-82.e1

19. American Dental Hygienists Association. Direct access states. June 2014. Available at: www.adha.org/ resources-docs/7513_Direct_Access_ to_Care_from_DH.pdf. Accessed September 9, 2015

20. American Dental Hygienists Association. Reimbursement. Available at: www.adha.org/reimbursement. Accessed September 9, 2015

21. American Dental Association. Dental Quality Alliance, 2012. Pediatric Oral Health Quality \& Performance Measures Concept Set: achieving standardization and alignment. Available at: www.ada. org/ /media/ADA/Science\%20and\%20 Research/Files/dqa_draft_starter_ measure_concept_set.ashx. Accessed July 20, 2015

22. Sams LD, Rozier RG, Wilder RS, Quinonez RB. Adoption and implementation of policies to support preventive dentistry initiatives for physicians: a national survey of Medicaid programs. Am J Public Health. 2013;103(8):e83-e90

23. Centers for Medicare \& Medicaid Services. Department of Health and Human Services EPSDT Data. CMS- 416 Instructions. Available at: medicaid.gov/medicaid-chip-programinformation/by-topics/benefits/ downloads/cms-416-instructions.pdf. Accessed July 22, 2015

24. Greene WH. Econometric Analysis. 5th ed. New York, NY: Prentice-Hall; 2002
25. Park HM. Linear regression models for panel data using SAS, Stata, LIMDEP, and SPSS. Working Paper. The University Information Technology Services (UITS) Center for Statistical and Mathematical Computing, Indiana University. Available at: www.indiana. edu/ statmath/stat/all/panel/panel. pdf. Accessed May 1, 2015

26. Park HM. Practical guides to panel data analysis. Available at: www.iuj. ac.jp/faculty/kucc625/writing/panel_ guidelines.pdf. Accessed May 1, 2015

27. Rozier RG, Sutton BK, Bawden JW, Haupt K, Slade GD, King RS. Prevention of early childhood caries in North Carolina medical practices: implications for research and practice. J Dent Educ. 2003;67 (8):876-885

28. Institute of Medicine. Committee on Quality Health Care in America. Crossing the Quality Chasm: A New Health System for the 21st Century. Washington, DC: The National Academies Press; 2003

29. Tabak RG, Khoong EC, Chambers DA, Brownson RC. Bridging research and practice: models for dissemination and implementation research. Am J Prev Med. 2012;43(3):337-350

30. Glasgow RE, Green LW, Taylor MV, Stange KC. An evidence integration triangle for aligning science with policy and practice. Am J Prev Med. 2012;42 (6):646-654

31. Vujicic M, Nasseh K. A decade in dental care utilization among adults and children (2001-2010). Health Serv Res. 2014;49(2):460-480

32. Nasseh K, Vujicic M. Dental care utilization rate highest ever among children, continues to decline among working-age adults. Research Brief. Health Policy Institute, American Dental Association. 2014. Available at: www. ada.org/ /media/ADA/Science\%20 and\%20Research/HPI/Files/HPIBrief_ 1014_4.ashx. Accessed August 1, 2015

33. Ku L, Sharac J, Bruen B, Thomas $M$, Norris L. Increased use of dental services by children covered by Medicaid: 2000-2010 Medicare Medicaid Res Rev. 2013;3(3):mmrr.003.03.b01

34. Hakim RB, Babish JD, Davis AC. State of dental care among 
Medicaid-enrolled children in the United States. Pediatrics. 2012;130(1):5-14

35. Grembowski D, Milgrom PM. Increasing access to dental care for medicaid preschool children: the Access to Baby and Child Dentistry (ABCD) program. Public Health Rep. 2000;115(5):448-459

36. Chou R, Cantor A, Zakher B, Mitchell JP, Pappas M. Prevention of Dental Caries in Children Younger Than 5 Years Old: Systematic Review to Update the U.S. Preventive Services Task Force Recommendation. Evidence Synthesis No. 104. AHRQ Publication No. 12-05170-EF-1.
Rockville, MD: Agency for Healthcare Research and Quality; 2014

37. Beil HA, Rozier RG. Primary health care providers' advice for a dental checkup and dental use in children. Pediatrics. 2010;126(2). Available at: www.pediatrics. org/cgi/content/full/126/2/e435

38. Long CM, Quinonez RB, Beil HA, et al. Pediatricians' assessments of caries risk and need for a dental evaluation in preschool aged children. BMC Pediatr. 2012;12(1):49

39. Kranz AM, Rozier RG, Preisser JS, Stearns SC, Weinberger M, Lee JY. Preventive services by medical and dental providers and treatment outcomes. J Dent Res. 2014;93(7):633-638

40. Schneider D, Rossetti J, Crall JC Assuring Comprehensive Dental Services in Medicaid and Head Start Programs: Planning and Implementation Considerations. National Oral Health Policy Center Technical Issue Brief. Los Angeles, CA: National Oral Health Policy Center; 2007

41. Medicaid: State and Federal Actions Have Been Taken to Improve Children's Access to Dental Services, But Gaps Remain. Washington, DC: US Government Accountability Office; 2009:GA0-09-GA0-723 


\section{Provision of Preventive Dental Services in Children Enrolled in Medicaid by Nondental Providers \\ Tania Arthur and R. Gary Rozier \\ Pediatrics 2016;137;}

DOI: 10.1542/peds.2015-3436 originally published online January 22, 2016;

\begin{tabular}{|c|c|}
\hline $\begin{array}{l}\text { Updated Information \& } \\
\text { Services }\end{array}$ & $\begin{array}{l}\text { including high resolution figures, can be found at: } \\
\text { http://pediatrics.aappublications.org/content/137/2/e20153436 }\end{array}$ \\
\hline References & $\begin{array}{l}\text { This article cites } 20 \text { articles, } 7 \text { of which you can access for free at: } \\
\text { http://pediatrics.aappublications.org/content/137/2/e20153436\#BIBL }\end{array}$ \\
\hline Subspecialty Collections & $\begin{array}{l}\text { This article, along with others on similar topics, appears in the } \\
\text { following collection(s): } \\
\text { Community Pediatrics } \\
\text { http://www.aappublications.org/cgi/collection/community_pediatrics } \\
\text { sub } \\
\text { Community Health Services } \\
\text { http://www.aappublications.org/cgi/collection/community_health_ser } \\
\text { vices_sub } \\
\text { Dentistry/Oral Health } \\
\text { http://www.aappublications.org/cgi/collection/dentistry:oral_health_s } \\
\text { ub }\end{array}$ \\
\hline Permissions \& Licensing & $\begin{array}{l}\text { Information about reproducing this article in parts (figures, tables) or } \\
\text { in its entirety can be found online at: } \\
\text { http://www.aappublications.org/site/misc/Permissions.xhtml }\end{array}$ \\
\hline Reprints & $\begin{array}{l}\text { Information about ordering reprints can be found online: } \\
\text { http://www.aappublications.org/site/misc/reprints.xhtml }\end{array}$ \\
\hline
\end{tabular}




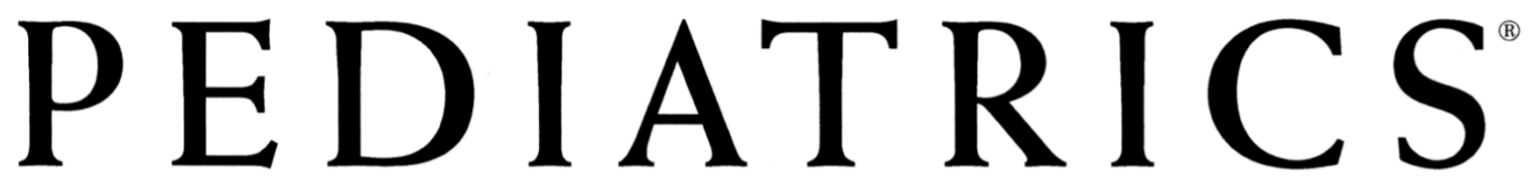

OFFICIAL JOURNAL OF THE AMERICAN ACADEMY OF PEDIATRICS

\section{Provision of Preventive Dental Services in Children Enrolled in Medicaid by Nondental Providers \\ Tania Arthur and R. Gary Rozier \\ Pediatrics 2016;137;}

DOI: 10.1542/peds.2015-3436 originally published online January 22, 2016;

The online version of this article, along with updated information and services, is located on the World Wide Web at: http://pediatrics.aappublications.org/content/137/2/e20153436

Pediatrics is the official journal of the American Academy of Pediatrics. A monthly publication, it has been published continuously since 1948. Pediatrics is owned, published, and trademarked by the American Academy of Pediatrics, 141 Northwest Point Boulevard, Elk Grove Village, Illinois, 60007. Copyright $\odot 2016$ by the American Academy of Pediatrics. All rights reserved. Print ISSN: 1073-0397. 